\title{
Numerical Simulation of Molten Slag Deposition in Radiant Syngas Cooler with a CFD-Based Model
}

\author{
Xianbin Li, Guangsuo Yu, Zhenghua DaI, Zhijie ZHou and \\ Fuchen WANG \\ Key Laboratory of Coal Gasification and Energy Chemical Engineering of \\ Ministry of Education, Shanghai Engineering Research Center of Coal Gasification, \\ East China University of Science and Technology, Meilong Road 130, Shanghai 200237, P. R. China
}

Keywords: Deposition, CFD, Radiant Syngas Cooler, Molten Slag

\begin{abstract}
A computational fluid dynamic (CFD) model and a deposition model are coupled to predict the molten slag deposition behavior in radiant syngas cooler (RSC) for entrained flow coal gasification. The slag particle deposition model is developed by identifying the excess rebound energy as a criterion to determine if the particle is deposited or rebounded from the wall while slag solidification in the impact process is also considered. The simulation results show that molten slag particles stick on the membrane wall between the height of 12.2-22.0 $\mathrm{m}$ for Reference Case with the maximum deposition rate $1.5 \times 10^{-5} \mathrm{~kg} /\left(\mathrm{m}^{2} \cdot \mathrm{s}\right)$ at the position of height about $16.8 \mathrm{~m}$. The deposition rate increases with increasing inlet temperature and operating load. Small inlet diameter leads to high deposition rate due to high transport rate and high deposit propensity, while small inner cylinder diameter leads to higher deposition rate due to higher deposit propensity.
\end{abstract}

\section{Introduction}

Entrained-flow gasifier, an important component in advanced integrated gasification combined cycle (IGCC) power plants, usually run at high temperatures of $1,200-1,600^{\circ} \mathrm{C}$ and high pressure of $2-8 \mathrm{MPa}$; most plants run at around 4.0 or $6.5 \mathrm{MPa}$ (Liu and Hao, 2007; Higman and van der Brugt, 2011). Two main methods are usually used for cooling the high temperature raw syngas along with molten slag and fly ash: water quench or radiant cooling (Minchener, 2005). Using a radiant syngas cooler (RSC) can recover the sensible heat of the syngas and molten slag. Most of the slag/ash can be captured by the slag pool at the bottom of RSC and removed through a lock hopper. However, some of the molten slag particles may stick on the surface of membrane wall which is cooled by water. Slagging not only reduces the thermal efficiency, but also affects its integrity as a result of corrosion, erosion or other negative impacts on the RSC's membrane wall.

The net deposition rate depends on both the rate of slag particles transport to a surface and their propensity to stick once they reach a surface. The chemical properties of slag are usually used to measure the fusibility (Liu and Hao, 2007), flow property (Xu et al., 2014a) and slagging propensity (Xu et al., 2009). Various studies are focus on analyzing the chemistry components of the ash and evaluating the deposition mechanism in coal-fired combustors (Naruse and Nakayama, 2000; Naruse et al., 2010), entrained flow gasifi-

Received on March 25, 2015; accepted on June 20, 2015 DOI: $10.1252 /$ jcej.15we035

Correspondence concerning this article should be addressed to G. Yu (E-mail address: gsyu@ecust.edu.cn). ers (Barroso et al., 2006, 2007) and syngas coolers (Brooker, 1993; Strandström et al., 2007). Slag viscosity is also commonly used as particle-sticking criteria to predict the results of the particle impact process (Richards et al., 1993; Fan et al., 2001). Various sticking probabilities of three different approaches: empirical viscosity models, experimental results based on ash fusion characteristic, thermo-gravimetry and thermodynamic equilibrium calculations are compared (Wieland et al., 2012). However, the impact of slag particles on the membrane wall is further complicated due to the slag solidification in impact process. Bussmann et al. (1999) developed a 3D, finite-difference, fixed-grid Eulerian model which used a volume-tracking algorithm to locate droplet free surface. Pasandideh-Fard et al. (2002) used the volume of fluid (VOF) model to simulate the impact process (Pasandideh-Fard et al., 1996) and modified the Bussmann's 3D model (Bussmann et al., 1999) by taking heat transfer and solidification into account. Li et al. (2010) studied the ash deposition behavior in the gasifier by combining the experiment and computational fluid dynamic (CFD) simulation. Yong et al. (2012), Yong and Ghoniem (2012), Chen et al. (2013) and Chen and Ghoniem (2013) predicted the slag layer characteristics and its influence on the wall heat transfer with the model coupled with a CFD model and particle capture model. Mechanical adhesion theories and viscoelastic modeling is combined to model ash particle deposition (Losurdo et al., 2012). The maximum spread diameter and rebound criterion are used in a slag droplet rebound model to predict the impact process, and the effects of slag viscosity, impact velocity, impact angle, molten slag surface tension, molten slag contact angle, and particle size are all considered (Ni et al., 2011a). However, in a RSC, the slag droplet impact velocity, impact angle, slag contact angle and 
wall temperature are variables of spatial location. Therefore, using the limited data from experiments, CFD simulation is applied to predict the molten slag deposition quantitatively under high temperature and high pressure conditions. Advanced CFD-based ash deposition models are combined with the thermochemical properties (Mueller et al., 2005), CCSEM data (Lee and Lockwood, 1999), multi-component and advanced fuel analyses (Zevenhoven-Onderwater et al., 2000) of the particles to predict the transport of fly ash particles quantitatively. Few researchers have predicted the deposition rate synthetically considering the effects of slag viscosity, impact velocity, impact angle, surface tension, particle size and the solidification in the impact process.

In this paper, an axisymmetric 2-D model of RSC is developed, the gas-solid flow is simulated numerically using the commercial CFD-code FLUENT, and the trajectory of slag particles is calculated. The rebound criterion is applied to predict the results of the slag impact processes when the slag particles reach the membrane wall surface by compiling the user defined functions (UDFs).

\section{Mathematical Model}

For comprehensive modeling of the gas-particle turbulent flow, heat transfer and slag deposit in the RSC is shown in Figure 1. The numerical methods for the physical processes, such as gas-particle flow, heat-transfer and slag particle impact process, in the present model are discussed in the following sections.

\subsection{Multiphase flow hydrodynamics}

In the present work, an Eulerian-Lagrangian method is adopted to describe the flow behavior of the gas and particle phases. The gas flow is simulated as turbulent, described by the realizable $k-\varepsilon$ model (Shih et al., 1995). This model can accurately predict the spreading rate of both planar and round jets and has been extensively validated (Ni et al., 2009). The syngas from gasifier is a mixture of many species, and the species transfer model is used to evaluate the gas species concentration distributions. In addition, the water gas shit reaction (WGSR) maybe occurred in RSC, but the effect on tempera-

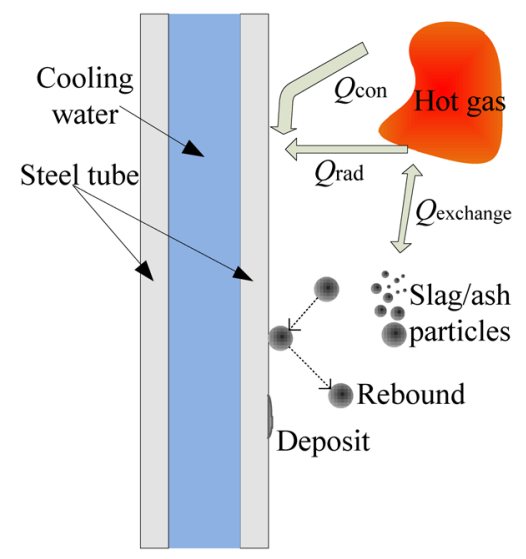

Fig. 1 Mechanisms of the physical processes in RSC ture and flow fields is small, so it is ignored.

The particle is assumed as spherical, and the particle volume fraction is about $10^{-4}$ or lower in RSC. So the interaction between the particles can be ignored (Wang et al., 2007). The particle motion can be described by the discrete random walk (DRW) model (Ni et al., 2011b). The trajectories of particles are predicted by integrating the force balance on a particle. According to Newton's second law of motion, the force balance can be represented as

$$
\frac{\mathrm{d} \vec{u}_{\mathrm{p}}}{\mathrm{d} t}=F_{\mathrm{D}}\left(\vec{u}_{\mathrm{g}}-\vec{u}_{\mathrm{p}}\right)+\frac{\vec{g}\left(\rho_{\mathrm{p}}-\rho_{\mathrm{g}}\right)}{\rho_{\mathrm{p}}}+F_{\mathrm{a}}
$$

Where $\vec{u}_{\mathrm{p}}$ is the particle velocity, $\vec{u}_{\mathrm{g}}$ is the syngas velocity, $\rho_{\mathrm{p}}$ is the particle density, $F_{\mathrm{a}}$ is an additional acceleration (force/unit particle mass) term including the virtual mass force, thermo-phoresis force, Brownian force and Saffman's lift force. These forces are ignored in this paper due to they are so small under the condition of RSC, $\rho_{\mathrm{g}} \ll \rho_{\mathrm{p}} . F_{\mathrm{D}}\left(\vec{u}_{\mathrm{g}}-\vec{u}_{\mathrm{p}}\right)$ is the drag force per unit particle mass and

$$
F_{\mathrm{D}}=\frac{18 \mu}{\rho_{\mathrm{p}} d_{\mathrm{p}}^{2}} \frac{C_{\mathrm{D}} R e}{24}
$$

where $\mu$ is viscosity of the fluid, $C_{\mathrm{D}}$ is the drag coefficient, $d_{\mathrm{p}}$ is the particle diameter and $R e$ is the relative Reynolds number that is defined as

$$
R e=\frac{\rho_{\mathrm{g}} d_{\mathrm{p}}\left|\vec{u}_{\mathrm{p}}-\vec{u}_{\mathrm{g}}\right|}{\mu}
$$

The interaction between the gas and particle phases is considered by the two-way coupling method. The momentum transfer from the continuous phase to the discrete phase is computed by examining the change in momentum of a particle as it passes through each control volume. The two-way coupling is accomplished by alternately solving the continuous and discrete phase equations until the solutions in both phases converge. The momentum change is computed as

$$
F=\sum\left(\frac{3 \mu C_{\mathrm{D}} R e}{4 \rho_{\mathrm{p}} d_{\mathrm{p}}^{2}}\left(u_{\mathrm{p}}-u_{\mathrm{g}}\right)+F_{\text {other }}\right) \dot{m}_{\mathrm{p}} \Delta t
$$

where $\dot{m}_{\mathrm{p}}$ is mass flow rate of the particles, $\Delta t$ is the time step and $F_{\text {other }}$ is other interaction forces.

\subsection{Heat-transfer model}

The radiative heat-transfer predominates in overall heat transfer process in the RSC shown in Figure 1, although convective and conductive heat transfer cannot be ignored. In this work, the radiative heat transfer equations are solved by the discrete ordinate (DO) model. Heat-transfer between the syngas and slag/ash particles is considered by solving the heat balance equation:

$$
m_{\mathrm{p}} C_{\mathrm{p}} \frac{\mathrm{d} T_{\mathrm{p}}}{\mathrm{d} t}=h A_{\mathrm{p}}\left(T_{\mathrm{g}}-T_{\mathrm{p}}\right)+\varepsilon_{\mathrm{p}} A_{\mathrm{p}} \sigma\left(\theta_{\mathrm{R}}^{4}-T_{\mathrm{p}}^{4}\right)
$$

where $\theta_{\mathrm{R}}$ is the radiation temperature which is calculated with the incident radiation $G$ and Stefan-Boltzmann con- 
stant $\sigma:(\mathrm{G} / 4 \sigma)^{0.25}$, and the convective heat transfer coefficient $h$ is evaluated by the correlation of Ranz and Marshall (1952). The heat lost or gained by the particle can be calculated based on the temperature and flow field as it traverses each computational cell.

\subsection{Collision mechanism}

As the change of important factors, such as liquid properties, surface characteristics, impact velocity and surface inclination, there are six regimes of particle-to-wall collision observed experimentally without phase transition (Šikalo et al., 2002, 2005): (1) splash, (2) spreading, (3) spreading and sliding, (4) partial rebound, (5) rebound, (6) deformation. However, in our study, the solidification in the collision process cannot be ignored because of the low temperature of membrane wall. Figure 2 shows five different results of the collision process of a single particle. When the temperature of slag particle is lower than the flow temperature (Figure 2(a)) when it impact the membrane wall, the particle is assumed to be solid and would rebound from the membrane wall after impact process as shown in Figure 2(a) and (b). When the temperature of slag particle is higher than flow temperature (Figure 2(c)), the particle is assumed to be molten and the rebound criterion is applied to predict the result of the slag impact process.

Mao et al. (1997) proposed that the droplet impact process can be divided into four stages and suggested that the rebound criterion can be determined by impact energy. This criterion has been applied to predict the carryover deposition in boilers (Mao et al., 1997) and the slag deposition processes (Ni et al., 2011a). Before impact (Figure 2(c)), the initial kinetic energy $\left(E_{\mathrm{k} 1}\right)$ and surface energy $\left(E_{\mathrm{s} 1}\right)$ of a droplet are

$$
\begin{aligned}
& E_{\mathrm{k} 1}=\frac{1}{2} m u_{0}^{2}=\frac{1}{2} \rho_{\mathrm{p}}\left(\frac{1}{6} \pi d_{\mathrm{p}}^{3}\right) u_{0}^{2} \\
& E_{\mathrm{s} 1}=A \gamma=\pi d_{\mathrm{p}}^{2} \gamma
\end{aligned}
$$

When the droplet reaches its maximum spread diam-

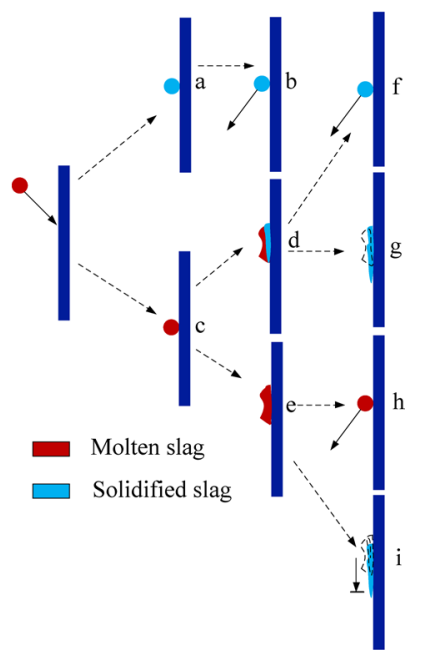

Fig. 2 Different collision results of a single particle eter $D_{\max }$ as shown in Figure 2(e), the kinetic energy is zero $\left(E_{\mathrm{k} 2}=0\right)$, and the surface energy $\left(E_{\mathrm{s} 2}\right)$

$$
E_{\mathrm{s} 2}=\frac{\pi}{4} D_{\max }^{2} \gamma(1-\cos \alpha)
$$

where $\alpha$ is the slag-solid contact angle. The work in deforming the droplet $(W)$ (Pasandideh-Fard et al., 1996) is

$$
W=\frac{\pi}{3} \rho_{\mathrm{p}} u_{0}^{2} d_{\mathrm{p}} D_{\max }^{2} \frac{1}{\sqrt{R e}}
$$

As shown in Figure 2(d), the molten slag may solidify when it reaches the cold membrane wall surface. Restricting the droplets spread due to the solidification is modeled by assuming that the kinetic energy stored in the solidified layer is lost. The loss $\left(\Delta E_{\mathrm{k}}\right)$ is approximated by

$$
\Delta E_{\mathrm{k}}=\left(\frac{\pi}{4} d_{\mathrm{s}}^{2} s\right)\left(\frac{1}{2} \rho_{\mathrm{p}} u_{0}^{2}\right)
$$

A reasonable estimate of $d_{\mathrm{s}}$ mean value is $D_{\max } / 2$. The thickness of the solidified layer is calculated using an approximate analytical solution developed by Poirier and Poirier (1992). The dimensionless solidification thickness is expressed as a function of Peclet number $\left(P e=u_{0} d_{\mathrm{p}} / \alpha\right)$, Stefan number $\left(\right.$ Ste $\left.=C\left(T_{\mathrm{m}}-T_{\mathrm{m}, i}\right) / H_{\mathrm{f}}\right)$ and $\phi=k_{\mathrm{p}} \rho C$

$$
\frac{s}{d_{\mathrm{p}}}=\frac{2}{\sqrt{\pi}} S t e \sqrt{\frac{t^{*} \phi_{\mathrm{w}}}{P e \phi_{\mathrm{d}}}}
$$

According to the energy balance law

$$
E_{\mathrm{k} 1}+E_{\mathrm{s} 1}=E_{\mathrm{k} 2}+E_{\mathrm{s} 2}+W+\Delta E_{\mathrm{k}}
$$

Substituting Eqs. (6)-(11) into Eq. (8) yields an expression for the maximum spread factor $\xi_{\max }$ :

$$
\xi_{\max }=\sqrt{\frac{W e+12}{W e S t e \sqrt{\frac{3 \phi_{\mathrm{w}}}{2 \pi P e \phi_{\mathrm{d}}}}+3(1-\cos \alpha)+\frac{4 W e}{\sqrt{R e}}}}
$$

where $W e$ is the Weber number $\left(W e=\rho_{\mathrm{p}} u_{0}^{2} d_{\mathrm{p}} / \gamma\right)$.

Hence, if the energy possessed by a droplet is large enough when reaching the maximum spread diameter, the droplet will further rebound up and be swept away by the strong shear force of syngas in the near wall regions as illustrated in Figure $2(\mathrm{c}-\mathrm{d}-\mathrm{f})$ and $(\mathrm{c}-\mathrm{e}-\mathrm{h})$. Therefore, a rebound criterion is formulated (Mao et al., 1997):

$$
\begin{aligned}
E_{\mathrm{e}}^{*}= & 0.25\left(\xi_{\max }\right)^{2}(1-\cos \alpha) \\
& -0.12\left(\xi_{\max }\right)^{2.3}(1-\cos \alpha)^{0.63}+2 /\left(3 \xi_{\max }\right)-1
\end{aligned}
$$

where $E_{\mathrm{e}}^{*}$ is the excess rebound energy which describes the tendency of a droplet to rebound up. A droplet remains on the membrane wall surface when $E_{\mathrm{e}}^{*} \leq 0$, Figure $2(\mathrm{c}-\mathrm{d}-\mathrm{g})$ and $(\mathrm{c}-\mathrm{e}-\mathrm{i})$, which is the slag deposition formation. The molten part of deposited slag would flow downward under the action of gravity and solidified finally. In this study, a UDF is compiled to calculate the $E_{\mathrm{e}}^{*}$ to predict the results of the slag droplet deposition processes once the slag particles contact the membrane wall surface. 


\subsection{Physical and thermal properties modeling}

The radiative properties of syngas are computed by a Weight Sum of Gray Gases Model (WSGGM) (Smith et al., 1982). The syngas density and the species mass diffusion coefficient of syngas can be calculated by the ideal gas mixtures law and multi-component Fick's law respectively. The radiative properties of slag particles are dependent on the chemical compositions, particle size, particle shape and surface roughness (Bhattacharya, 2000). The composition and physical properties of slag particles in the present work are shown in Table $\mathbf{1}$.

The slag viscosity changes with temperature $\left(T_{s},{ }^{\circ} \mathrm{C}\right)$ for the Ningxia coal shown in Figure 3, the experimental data is obtained from the high temperature viscometer (Xu et al., 2014b) under reducing atmosphere, and the fitted expression is

$$
\mu=7.772+12370.74 /\left[1+\exp \left(\frac{T_{\mathrm{s}}-1208.37}{13.15}\right)\right]
$$

Surface tension of coal slag is dependent on the chemical compositions, atmosphere, temperature and pressure (Melchior et al., 2009, 2011). Typical coal slags exhibited surface tension values between $400-700 \mathrm{mN} / \mathrm{m}$ (Melchior et al.,

Table 1 Composition and properties of Ningxia coal ash/slag

\begin{tabular}{lrcc}
\hline Component & wt $/ \%$ & \multicolumn{2}{c}{ Ash fusion temperatures $\left[{ }^{\circ} \mathrm{C}\right]$} \\
\hline $\mathrm{SiO}_{2}$ & 40.24 & $\mathrm{DT}$ & 1,118 \\
$\mathrm{Fe}_{2} \mathrm{O}_{3}$ & 7.69 & $\mathrm{ST}$ & 1,145 \\
$\mathrm{Al}_{2} \mathrm{O}_{3}$ & 17.57 & $\mathrm{HT}$ & 1,155 \\
$\mathrm{TiO}_{2}$ & 0.96 & $\mathrm{FT}$ & 1,164 \\
$\mathrm{CaO}$ & 13.43 & Physical properties & \\
\cline { 3 - 4 } $\mathrm{MgO}$ & 5.81 & Density $\left[\mathrm{kg} / \mathrm{m}^{3}\right]$ & 2,700 \\
$\mathrm{SO}_{3}$ & 9.87 & Slag conductivity $[\mathrm{W} /(\mathrm{m} \cdot \mathrm{K})]$ & 1.87 \\
$\mathrm{P}_{2} \mathrm{O}_{5}$ & 0.04 & Scattering $[1 / \mathrm{m}]$ & 0.10 \\
$\mathrm{~K}_{2} \mathrm{O}$ & 1.58 & Emissivity & 0.83 \\
$\mathrm{Na}_{2} \mathrm{O}$ & 2.14 & Heat capacity $[\mathrm{J} /(\mathrm{kg} \cdot \mathrm{K})]$ & 1,450 \\
Others & 0.67 & T $T_{\text {cv }}\left[{ }^{\circ} \mathrm{C}\right]$ & 1,280 \\
\hline
\end{tabular}

Ash fusion temperatures are measured under reducing conditions. DT: initial deformation temperature, ST: spherical temperature, HT: Hemispherical temperature, FT: fluid temperature.

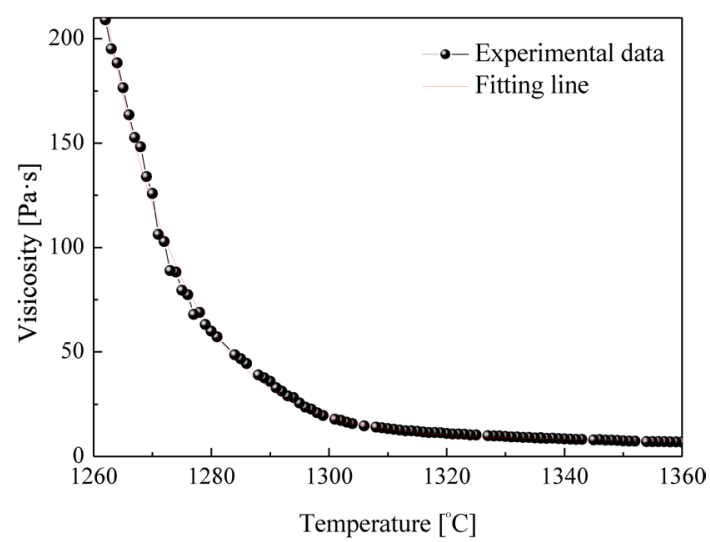

Fig. 3 Viscosity-temperature data of the Ningxia coal slag under reducing atmosphere with the fitted curve fitted
2009) under reducing atmosphere. Due to the simplification of mathematical model, the surface tension $\gamma$ of Ningxia Coal slag is estimated $(\gamma=500 \mathrm{mN} / \mathrm{m})$ based on the surface tension range and the operating condition of RSC. The contact angle can be presented as a function of the wall temperature fitted by the following Boltzmann fitting equation.

$$
\alpha=a+(b-a) /\left\{1+\exp \left[\left(T_{\mathrm{w}}-c\right) / d\right]\right\}
$$

where $T_{\mathrm{w}}$ is the substrate temperature, the constants $a=54.80, b=104.37, c=347.53$, and $d=117.93$, the values are suggested by Ni et al. (2011a) from the literature (Abbott and Austin, 1985).

\section{Boundary Conditions and Simulation Method}

The RSC geometry is illustrated in Figure 4(a), which is designed for an industrial-scale coal-water slurry entrained flow gasifier. Typical operating condition given in Table 2 is obtained from an industrial entrained flow gasification plant. This paper investigates mainly the deposition characteristics of molten slag in RSC, and the deposition occurs in the inner cylinder. In order to simplify the model, the system is composed of the inlet and the inner cylinder. Due to the axisymmetric system, the computational domain, containing 87,100 cells (Reference case (RC): $D_{\text {inlet }}=1.05 \mathrm{~m}$ and $D_{\text {inner }}=2.5 \mathrm{~m}$ ) as shown in Figure $4(\mathbf{b})$, is divided by quad grids with mesh refinement near the membrane wall. The specified grid is fine enough to give grid independent solution and be validated through the grid-independent tests. The mass inlet and pressure outlet are used for inlet and outlet boundary, respectively. The surface inlet is used for particle inlet, and the inlet velocity is the same as gas. The surface temperature of each membrane wall is determined from energy balance equations based on the thickness of ash and slag accumulation by compiling UDFs. The ash or slag accumulation condition, as shown in Figure 5, only can be observed and examined when the gasifier unit is shutdown. There exists no slag and thin ash accumulation under normal shutdown for spare part replacement and maintenance as shown in Figure 5(a) which is taken from an industrial RSC in one methanol plant. Figure 5(b), taken from the same RSC, shows the severe slag deposit at the top section and it may lead to blockage requiring gasification plant to be dropped out of service for cleaning or repair. In this paper, refer to Figure 5(a), the thicknesses of ash accumulation on wall-up and wall-inner for RC in Figure 4 were estimated to be $0.2 \mathrm{~mm}$ and $0.3 \mathrm{~mm}$, respectively. The measured particle size distribution is shown in Figure 6. The Rosin-Rammlar

Table 2 Operating conditions of industrial-scale RSC (RC)

\begin{tabular}{lr}
\hline \multicolumn{1}{c}{ Variable } & \multicolumn{1}{c}{ Value } \\
\hline Syngas and particle inlet temperature $\left[{ }^{\circ} \mathrm{C}\right]$ & $1,364.0$ \\
Temperature of water in slag pool $\left[{ }^{\circ} \mathrm{C}\right]$ & 47.0 \\
Operating pressure $[\mathrm{MPa}]$ & 4.0 \\
Inlet syngas flow rate $[\mathrm{kmol} / \mathrm{h}]$ & $10,593.1$ \\
Inlet particle mass flow rate $[\mathrm{kg} / \mathrm{h}]$ & $13,243.7$ \\
\hline
\end{tabular}




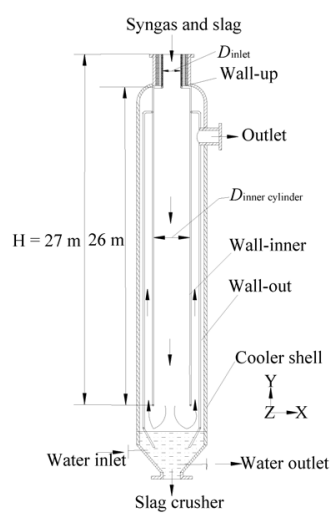

(a)

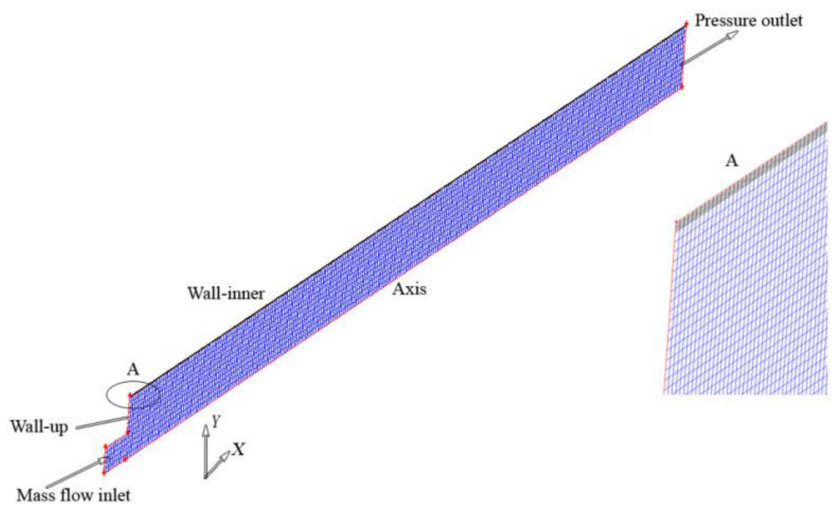

(b)

Fig. 4 Schematic diagram of (a) RSC for an entrained-flow gasifier and (b) computational grid

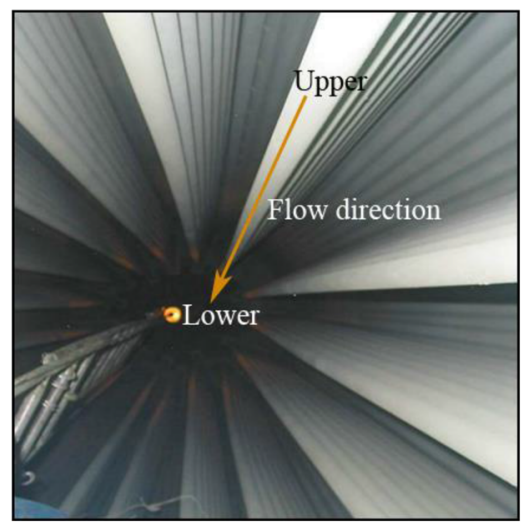

(a)

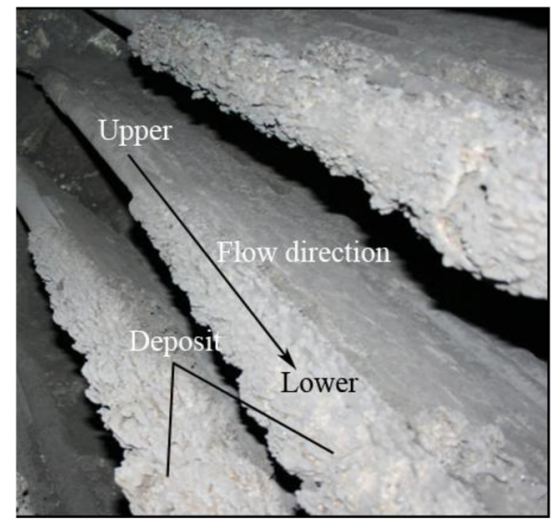

(b)

Fig. 5 Ash and slag deposition on membrane wall of an industrial RSC

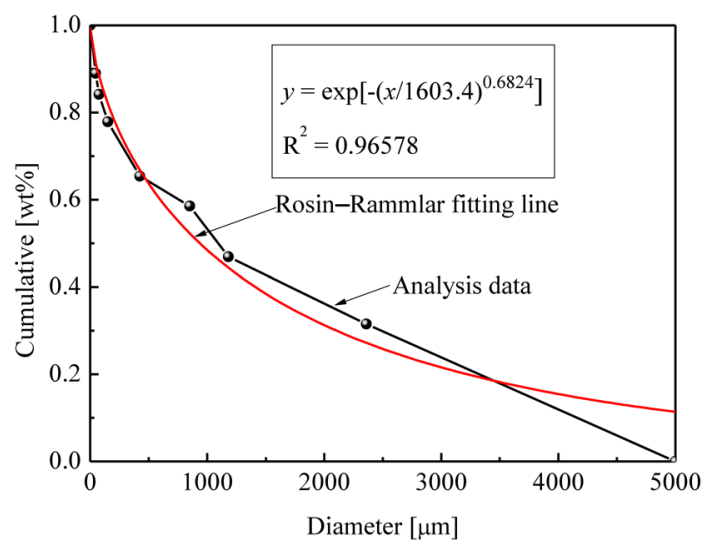

Fig. 6 Slag particle size distribution and Rosin-Rammlar fitting line

distribution method fitting to measurement data which is used for model calculation are also shown in Figure 6.

The governing equations for the conservation of momentum, energy, turbulence and radiation are solved sequentially by the finite-volume-method (FVM) using a commercial CFD code FLUENT 12.1 (ANSYS, Inc.). The standard wall function method (Launder and Spalding, 1974) is used to account for the near-wall effects in the flow field. For the evaluation of the convective terms and turbulent kinetic energy, the second order QUICK scheme is used. The PRESTO! Scheme is used for pressure discretization. For numerical stability, the first order upwind scheme is applied to solve the equations of gas species transport.

\section{Results and Discussion}

\subsection{Model validation}

In this CFD-based model, the flow and heat transfer model has been applied and validated (Ni et al., 2011b), and the droplet collision mechanism has been tested and validated by Aziz and Chandra (2000). This article only validates whether the collision mechanism is practicable for CFD model calculation. Numerical calculations have been carried out with this CFD-based model for a laboratory scale entrained flow reactor as described in (Wieland et al., 2012). The simulation results of the deposition rate on the probe which is inserted at the bottom of the entrained flow reactor, are shown in Figure 7, the maximum deposition rate is $7.95 \times 10^{-5} \mathrm{~kg} /\left(\mathrm{m}^{2} \cdot \mathrm{s}\right)$. As ignoring the influence on the flow and temperature field caused by chemical reaction, certain deviation exists while the experimental data is 


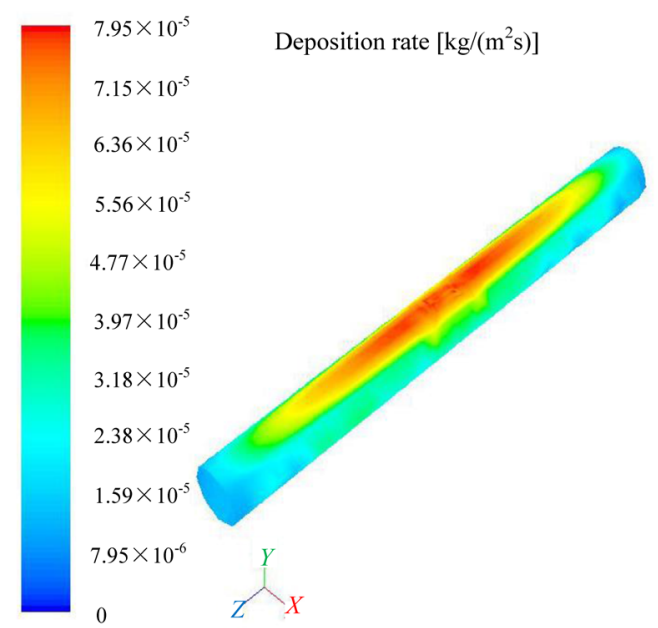

Fig. 7 Particle deposition rate on the probe surface in the entrained flow reactor with this CFD-based model

$3.63 \times 10^{-5} \mathrm{~kg} /\left(\mathrm{m}^{2} \cdot \mathrm{s}\right)$ obtained from (Wieland et al., 2012). Hence, using the present model, the predicted value can basically agree with the experimental result for deposition behavior of molten slag.

\subsection{Molten slag deposition}

Figure 8 shows the impact rate and deposition rate of particles impacting the membrane wall with the different inlet temperatures. Focus on the curves of RC $\left(T_{\text {inlet }}=1,637 \mathrm{~K}\right)$, the deposition occurs between the height of $11.2-22.0 \mathrm{~m}$ with the maximum deposition rate $1.5 \times 10^{-5} \mathrm{~kg} /\left(\mathrm{m}^{2} \cdot \mathrm{s}\right)$ at the position of height about $16.8 \mathrm{~m}$. The accumulate rate reaches $0.48 \mathrm{~mm} / \mathrm{d}$ (accumulation thickness per day) at the maximum deposition position while the molten slag flow behavior (Figure 2(i)) is neglected. The impact rate mainly dependents on the flow field and temperature field which are shown in Figure 9. Recirculation regions can be found around the inlet jet, and are shown clearly by streamlines with arrows. The long residence time of the syngas that enters into the recirculation regions causes lower temperature, and that can be verified by the temperature contour in Figure 9. Between the two recirculation regions, due to the circumfluence, the particles impact membrane wall time and again because rebounding happens while the temperature of impacting particles are lower than the slag flow temperature (Figure 2(a,b)). Hence, the impact rate reaches the maximum rate at height about $24.7 \mathrm{~m}$. The impact rate remains at high level because of the dissipation of inlet jet, and becomes lower while the jet flow turns to plug flow.

The deposit propensity $\eta$ of the impacting particles, as shown in Figure $\mathbf{1 0}$ can be calculated as:

$$
\eta=\frac{\text { Deposition Rate }}{\text { Impact Rate }}
$$

The fitting line for the deposit propensity is similar to the curve of deposition rate. The volumetrically weighted average properties of impacting particles are also shown

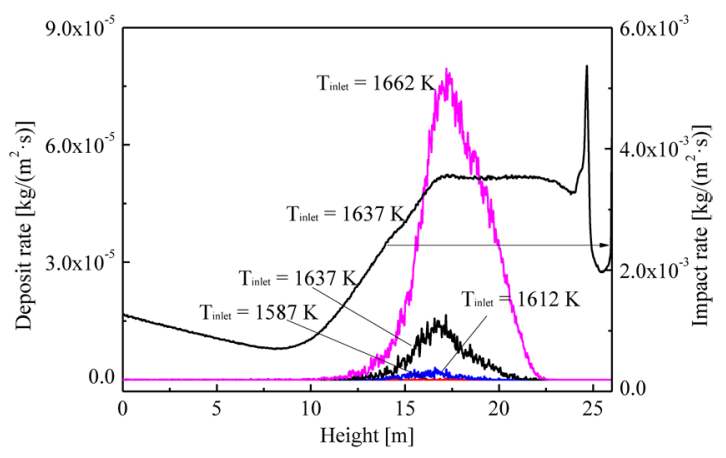

Fig. 8 Impact rate and deposition rate under different inlet temperatures
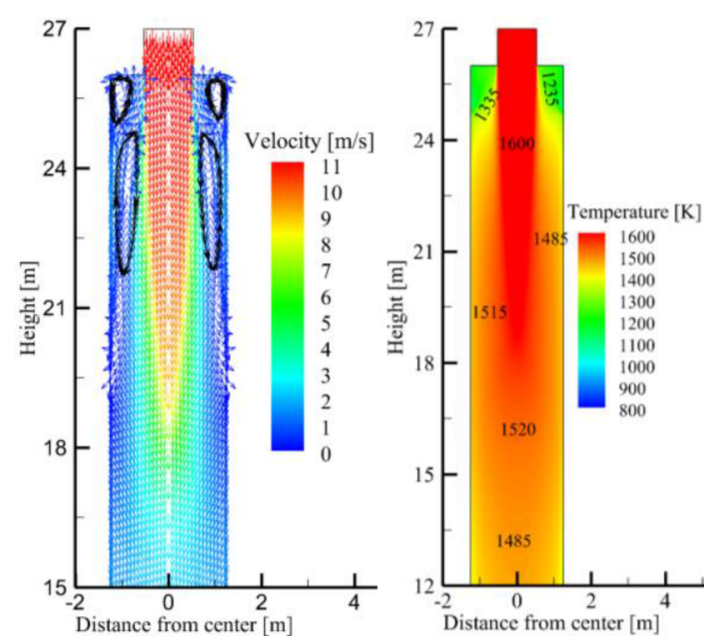

Fig. 9 Fluid velocity vectors and temperature contour at the top section of RC

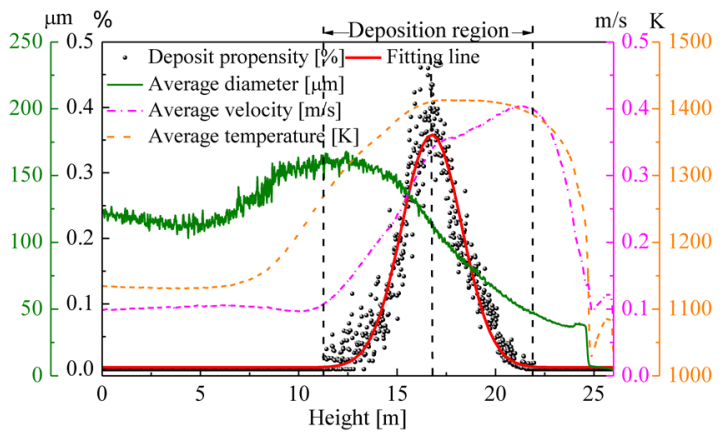

Fig. 10 Deposit propensity and average properties of particles impacting the membrane wall for RC

in Figure 10. The particle impact rate is high at the regions above height $22.0 \mathrm{~m}$ where no particle is captured because of the low temperature of the impacting particles while they are all solidified. The deposit propensity increases from the height 22.0 to $17.0 \mathrm{~m}$ with the maximum deposit mass percent $0.45 \%$. The impact temperature increase and velocity decrease of impacting particles leads to this rise trend in this region. Although the impact velocity still slow down, the particle impact rate reduce and the temperature decrease lead to the decrease of deposition rate. As show in Figure 
5(b), it is observed that the slag deposition always appear at the upper portion of membrane wall in the industrial RSC. This phenomenon can be another verification of the present model. Below the height $11.2 \mathrm{~m}$, all the impacting particles are solidified and considered to be inviscid.

\subsection{Effect of inlet temperature}

To clarify the effects of inlet temperature on the deposition rate, simulations with four inlet temperatures of 1,587-1,662 K were conducted. The comparison of the predicted results of different inlet temperatures is illustrated in Figure 8. Figure 11 illustrates the average temperature of impacting particles for different inlet temperatures. From the simulation results, the inlet temperature does have influence on the deposition rate, while the impact rates are almost same. It is found that the average temperature of impacting particles increases with the inlet temperature increasing correspondingly. The sticking probability becomes higher when more slag particles have not been solidified once they impact the membrane wall due to the higher inlet temperature. In addition, slag surface tension and viscosity are both functions of particle temperature. The viscosity decreases and the surface tension increases as the particle temperature increases. Hence, the tendency to rebound decreases as the temperature of impacting particles increases. These predictions are in agreement with $\mathrm{Ni}$ et al. (2011a) and Walsh et al. (1990).

In Figure $11, l_{1}$ and $l_{2}$ show the deposition region of RC, and points 2 and $2^{\prime}$ are the crossing points of deposition curve for $\mathrm{RC}\left(T_{\text {inlet }}=1,637 \mathrm{~K}\right)$ and $\mathrm{l}_{1}, \mathrm{l}_{2}$, respectively. Lines $l_{3}$ and $l_{4}$ are perpendicular to the vertical coordinate axes through the points 2 and $2^{\prime}$. Then 1, 1', 3 and $3^{\prime}$ are the crossing points as shown in Figure 11. The average temperature of impacting particles for $T_{\text {inlet }}=1,587 \mathrm{~K}$ is lower than others and no point exist curve of $T_{\text {inlet }}=1,587 \mathrm{~K}$ crossing $l_{3}$. Hence, the slag particles can hardly stick to the membrane wall which agrees with the result obtained from Figure 8. It can be attributed by the fact that the temperature of all particles impacting the membrane wall is lower than the molten temperature, and the particles are solidified and considered to be inviscid. When the inlet temperature is higher than

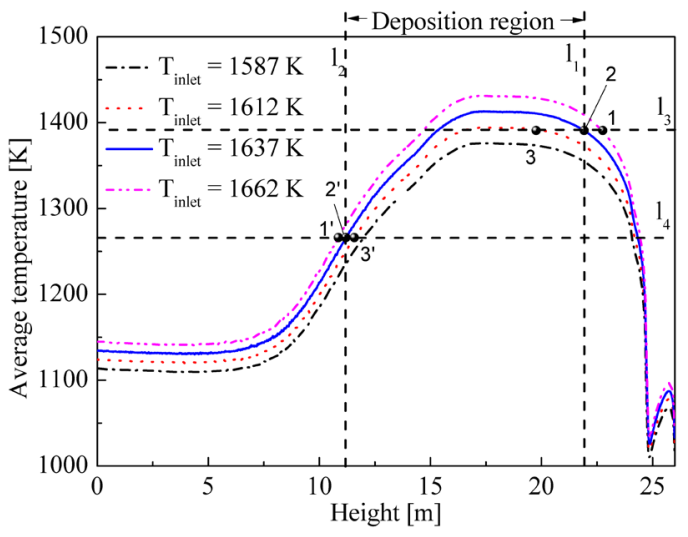

Fig. 11 Volumetrically weighted average temperature of impacting particles for different inlet temperatures
$1,612 \mathrm{~K}$, the regions $1-1^{\prime}, 2-2^{\prime}$ and $3-3^{\prime}$ are similar to the regions obtained from Figure 8. Hence, the temperature of $l_{3}$ can be defined as critical deposit temperature. In addition, the regions widen and the deposition rate increases as the inlet temperature increases. The deposition occurs between the height of 12.5-19.7 $\mathrm{m}$ with the maximum deposition rate $2.8 \times 10^{-6} \mathrm{~kg} /\left(\mathrm{m}^{2} \cdot \mathrm{s}\right)$ at the position of height about $16.7 \mathrm{~m}$ for $T_{\text {inlet }}=1,612 \mathrm{~K}$; the deposition region become wider, $10.0-22.5 \mathrm{~m}$ height, with a larger maximum deposition rate $7.8 \times 10^{-5} \mathrm{~kg} /\left(\mathrm{m}^{2} \cdot \mathrm{s}\right)$ at the position of height about $17.2 \mathrm{~m}$ for $T_{\text {inlet }}=1,662 \mathrm{~K}$.

\subsection{Effect of operating load}

In order to investigate the effects of operating load on the deposition rate, simulations for three more cases with different operating loads (95, 105 and $110 \%$ capacity of RC) were conducted. The syngas flow rate and the slag mass flow rate change accordingly with the change of operating loads. Figure 12(a) shows the impact and deposition rate of particles impacting the membrane wall with different operating loads. The significantly different slag flux leads to different impact and deposition rates. The increase of operating loads results in widening of deposition regions, increasing of the deposition rates. The impact rate increases as the syngas and slag flow rate rises correspondingly with the increase of operating load as shown in Figure 12(a). It also can be noted that the increment scale of deposition rate is larger than the

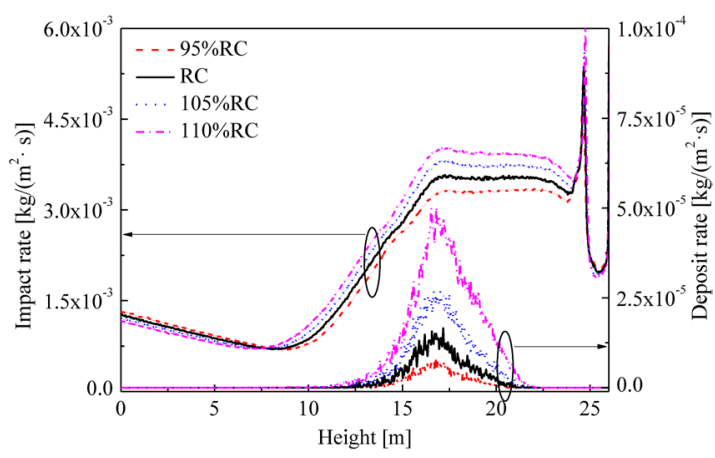

(a)

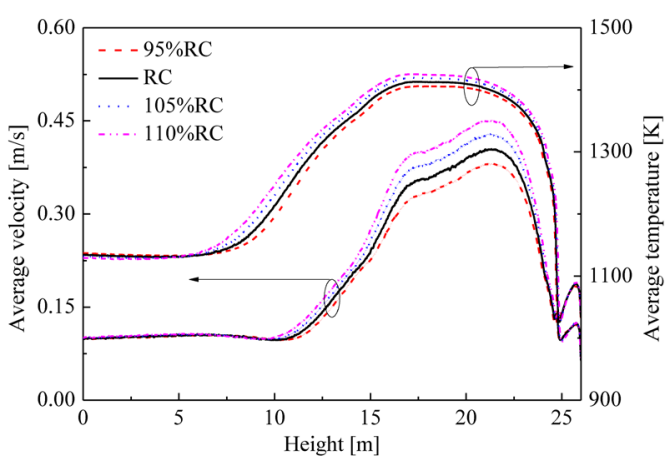

(b)

Fig. 12 Simulation results for different operating loads (95\%RC: 95\% capacity of RC)

(a) Average velocity and temperature; (b) impact and deposition rates. 
ratio of capacities. Figure 12(b) exhibits the average impacting velocity and temperature for different operating loads. It's found that the impact velocity increases due to inlet velocity increasing with operating load accordingly. The excess rebound energy increases with an increasing of the impact velocity from 0.1 to $1.0 \mathrm{~m} / \mathrm{s}$ ( $\mathrm{Ni}$ et al., 2011a). The particles with high velocity rebound from the membrane wall when they have positive excess rebound energy. However, due to the same heat transfer condition, larger load leads to the increase of impact temperature. Hence, in the deposition regions, the larger capacity case, the higher deposition propensity.

Based on the upper two sections, it can be inferred that the ash accumulation, which primarily affects the heat transfer condition, can cause serious slag deposition when the ash accumulation is thick. So in industrial scale gasification system, the soot blowers must be in good efficiency.

\subsection{Effect of structural parameter}

To investigate the effects of diameters of inlet and inner cylinder, the calculations of five structures were conducted. The structural parameters and expansion ratio $\left(D_{\text {inner }} / D_{\text {inlet }}\right)$ are listed in Table 3. From the calculations of cases with

Table 3 Structural parameters of different cases

\begin{tabular}{llllll}
\hline & Case 1 & Case 2 & RC & Case 3 & Case 4 \\
\hline$D_{\text {inlet }}[\mathrm{m}]$ & 0.95 & 0.85 & 1.05 & 1.05 & 1.05 \\
$D_{\text {inner }}[\mathrm{m}]$ & 2.5 & 2.5 & 2.5 & 2.2 & 2.8 \\
$D_{\text {inner }} / D_{\text {inlet }}$ & 2.63 & 2.94 & 2.38 & 2.10 & 2.67 \\
\hline
\end{tabular}

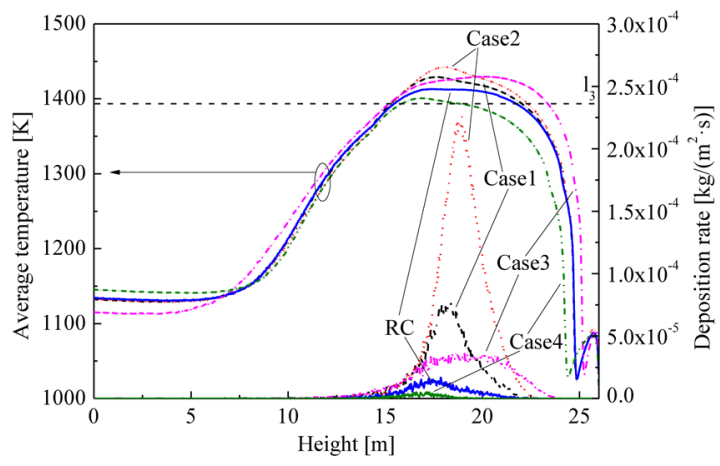

(a)

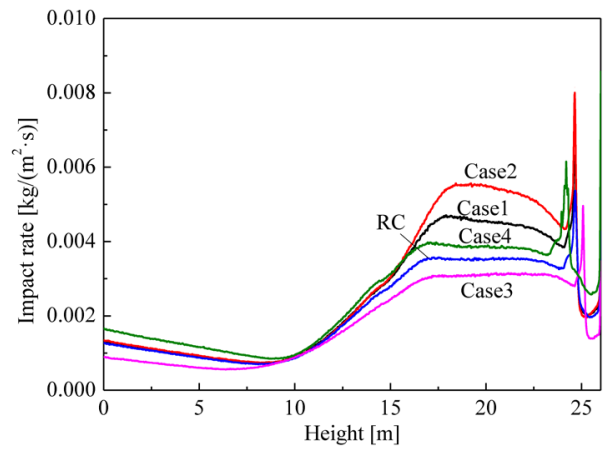

(b)

Fig. 13 Simulation results for different structural parameters same diameter of inner cylinder but different expansion radios (Case 1, Case 2 and RC), the deposition rate, as shown in Figure 13(a), is affected by inlet diameter through changing the inlet velocity. More molten slag particles would be carried to membrane wall as a result of higher inlet velocity due to the smaller inlet diameter. The Impact rate increases with the increase of expansion ratio as shown in Figure 13(b). On the basis of the higher inlet velocity, it can be deduced that particle would get a higher impacting temperature with less time for cooling and it can be observed in Figure 13(a). Due to the higher impact rate and impacting temperature, Case 2 has largest deposition rate compared to $\mathrm{RC}$ and Case 1 with a maximum rate $2.24 \times 10^{-4} \mathrm{~kg} /\left(\mathrm{m}^{2} \cdot \mathrm{s}\right)$, amount to $7.17 \mathrm{~mm} / \mathrm{d}$ which is unacceptable for industrial gasification system.

The diameter of inner cylinder also has influence on deposition rate. Due to the smaller circulation zone as inner cylinder diameter decreases, fewer particles are entrained to the membrane wall under the effect of inlet jet as shown in Figure 13(b). So Case 3 has a smaller impact rate than RC, while Case 4 has a bigger one than RC. Deviate from the effect of inlet diameter, the key factor affected by the inner cylinder diameter is the impacting temperature of particles. Positive correlation exists between the heat transfer area and inner cylinder diameter. In addition, it takes less time to reach the membrane wall for molten slag particles in Case 3 because of the small diameter inner cylinder. Hence, Case 3 has the highest impacting temperature, and the highest deposit propensity. Combined the upper two factors, deposition rate of Case 3 is larger than RC. There exists small region of the impacting temperature of Case 4 upper the critical deposit temperature $1_{3}$. Few particles in Case 4 deposit on the membrane wall though the impact rate is larger. Due to the higher impacting temperature, smaller inner cylinder diameter leads to higher deposit propensity and higher deposition rate.

\section{Conclusions}

An axisymmetric 2-D CFD-based numerical model has been described, and validated for predicting the deposition behavior of molten slag in RSC for the entrained-flow gasifier. The deposition conditions for different operating conditions and structural parameters were obtained by numerical simulation. The simulation results can be summarized as follows:

1. The industrial-scale RSC is simulated using the CFDbased model. In RC, some slag particles stick on the membrane wall between the heights of $12.2-22.0 \mathrm{~m}$ with the maximum deposition rate $1.5 \times 10^{-5} \mathrm{~kg} /\left(\mathrm{m}^{2} \cdot \mathrm{s}\right)$ at the position of height about $16.8 \mathrm{~m}$, which equals to $0.48 \mathrm{~mm} / \mathrm{d}$.

2. The slag can hardly stick on the membrane wall when the inlet temperature is $1,587 \mathrm{~K}$. Simulation results indicate that the sticking probability becomes higher as the inlet temperature increase. For the inlet temperature higher than $1,612 \mathrm{~K}$, the increase of it results in increase 
of deposition rates and widening of the deposition regions. The increase of operating loads results in increase of deposition rates and widening of the deposition regions by increasing the average temperature and impacting rate correspondingly.

3. More molten slag particles will stick on the membrane wall due to the stronger inlet jet while the inlet diameter becomes smaller. Combined with the higher impacting temperature, smaller inlet diameter leads to higher deposition rate. Due to the higher impacting temperature, smaller inner cylinder diameter leads to higher deposit propensity.

\section{Acknowledgements}

This work is financially supported by the National Nature Science Foundation of China (21176078) and National High Technology Research and Development of China (863 program, 2012AA053101).

\section{Nomenclature}

$A_{\mathrm{p}} \quad=$ surface area of the particle

$C_{\mathrm{D}}=$ drag coefficient

$C_{\mathrm{p}} \quad=$ specific heat capacity of particle

$D_{\max }=$ droplet maximum spread diameter

$d_{\mathrm{p}} \quad=$ diameter of the particle

$E_{\mathrm{e}}^{*} \quad=$ excess rebound energy

$E_{\mathrm{k}} \quad=$ kinetic energy

$E_{\mathrm{s}} \quad=$ surface energy

$F_{\mathrm{a}} \quad=$ additional acceleration term

$F_{\mathrm{D}}=$ drag force coefficient of the particle

$h_{\mathrm{f}}, h=$ convective heat-transfer coefficient

$k_{\mathrm{p}}=$ thermal conductivity of the particles

$m_{\mathrm{p}} \quad=$ mass of particle

$\dot{m}_{\mathrm{p}} \quad=$ mass flow rate of the particles

$\mathrm{Pe} \quad=$ Peclet number

Re $=$ relative Reynolds number

$s \quad=$ thickness of solidified layer

Ste $=$ Stefan number

$t \quad=$ temperature

$T=$ temperature

$T_{\mathrm{g}} \quad=$ temperature of gas

$T_{\mathrm{p}} \quad=$ temperature of particle

$T_{\mathrm{w}}=$ temperature of membrane wall surface

$u_{\mathrm{g}} \quad=$ gas velocity

$u_{\mathrm{p}} \quad=$ particle velocity

$u_{0} \quad=$ impact velocity

$W \quad=$ work performed in deforming the droplet against viscosity

We = Weber number

$x=$ spatial coordinate

$\alpha=$ contact angle

$\Delta E_{\mathrm{k}}=$ loss of kinetic energy

$\varepsilon_{\mathrm{p}} \quad=$ surface emissivity

$\gamma \quad=$ molten slag surface tension

$\eta \quad=$ Deposit propensity

$\mu \quad=$ molecular viscosity

$\theta_{\mathrm{R}}=$ radiation temperature

$\rho_{\mathrm{g}} \quad=$ gas density

$\rho_{\mathrm{p}} \quad=$ particle density $\sigma \quad=$ Stefan-Boltzmann constant $5.67 \times 10^{-8}$

$\xi_{\max }=$ Dimensionless maximum spread diameter

$\left[\mathrm{W} \mathrm{m} \mathrm{m}^{-2} \mathrm{~K}^{-4}\right]$

$[-]$

\section{Literature Cited}

Abbott, M. F. and L. G. Austin; "Studies on Slag Deposit Formation in Pulverized-Coal Combustors: 6. Sticking Behaviour of Slag Drops from Three Pennsylvania Steam Coals," Fuel, 64, 832-838 (1985)

Aziz, S. D. and S. Chandra; "Impact, Recoil and Splashing of Molten Metal Droplets," Int. J. Heat Mass Transfer, 43, 2841-2857 (2000)

Barroso, J., J. Ballester, L. M. Ferrer and S. Jiménez; "Study of Coal Ash Deposition in an Entrained Flow Reactor: Influence of Coal Type, Blend Composition and Operating Conditions," Fuel Process. Technol., 87, 737-752 (2006)

Barroso, J., J. Ballester and A. Pina; "Study of Coal Ash Deposition in an Entrained Flow Reactor: Assessment of Traditional and Alternative Slagging Indices," Fuel Process. Technol., 88, 865-876 (2007)

Bhattacharya, S.; "A Theoretical Investigation of the Influence of Optical Constants and Particle Size on the Radiative Properties and Heat Transfer Involving Ash Clouds and Deposits," Chem. Eng. Process. Process Intensif., 39, 471-483 (2000)

Brooker, D.; "Chemistry of Deposit Formation in a Coal Gasification Syngas Cooler," Fuel, 72, 665-670 (1993)

Bussmann, M., J. Mostaghimi and S. Chandra; "On a Three-Dimensional Volume Tracking Model of Droplet Impact," Phys. Fluids, 11, 1406-1417 (1999)

Chen, L., S. Z. Yong and A. Ghoniem; "Modeling the Slag Behavior in Three Dimensional CFD Simulation of a Vertically-Oriented OxyCoal Combustor," Fuel Process. Technol., 112, 106-117 (2013)

Chen, L. and A. Ghoniem; "Development of a Three-Dimensional Computational Slag Flow Model for Coal Combustion and Gasification," Fuel, 113, 357-366 (2013)

Fan, J. R., X. D. Zha, P. Sun and K. F. Cen; "Simulation of Ash Deposit in a Pulverized Coal-Fired Boiler," Fuel, 80, 645-654 (2001)

Higman, C. and M. van der Brugt; Gasification, Gulf Professional Publishing, Burlington, U.S.A. (2011)

Launder, B. E. and D. B. Spalding; "The Numerical Computation of Turbulent Flows," Comput. Methods Appl. Mech. Eng., 3, 269-289 (1974)

Lee, F. and F. Lockwood; "Modelling Ash Deposition in Pulverized Coal-Fired Applications," Pror. Energy Combust. Sci., 25, 117-132 (1999)

Li, S. H., Y. X. Wu and K. J. Whitty; "Ash Deposition Behavior During Char-Slag Transition under Simulated Gasification Conditions," Energy Fuels, 24, 1868-1876 (2010)

Liu, S. and Y. L. Hao; "A Critical Review of Slag Properties of Chinese Coals for Entrained Flow Coal Gasifier," Int. Mech. Eng. Congress Expo., pp. 83-92, Seattle, U.S.A. (2007)

Losurdo, M., H. Spliethoff and J. Kiel; "Ash Deposition Modeling Using a Visco-Elastic Approach," Fuel, 102, 145-155 (2012)

Mao, T., D. C. S. Kuhn and H. Tran; "Spread and Rebound of Liquid Droplets upon Impact on Flat Surfaces," Am. Inst. Chem. Eng., 43, 2169-2179 (1997)

Melchior, T., G. Putz and M. Muller; "Surface Tension Measurements of Coal Ash Slags under Reducing Conditions at Atmospheric Pressure," Energy Fuels, 23, 4540-4546 (2009)

Melchior, T., M. Blasing, G. Putz and M. Muller; "Surface Tension Measurements of Coal Ash Slags under Reducing Conditions at Elevated Pressures," Fuel, 90, 280-287 (2011)

Minchener, A. J.; "Coal Gasification for Advanced Power Generation," Fuel, 84, 2222-2235 (2005)

Mueller, C., M. Selenius, M. Theis, B. Skrifvars, R. Backman, M. Hupa 
and H. Tran; "Deposition Behaviour of Molten Alkali-Rich Fly Ashes-Development of a Submodel for CFD Applications," Proc. Combust. Inst., 30, 2991-2998 (2005)

Naruse, I. and K. Nakayama; "Ash Deposition Characteristics in Pulverized Coal Reaction under High Temperature Conditions," J. Chem. Eng. Japan, 33, 359-364 (2000)

Naruse, I., R. Yoshiie, M. Matsuura, Y. Ueki, H. Naganuma and T. Ito; "Control of Ash Deposition in Pulverized Coal Combustor," J. Chem. Eng. Japan, 43, 872-879 (2010)

Ni, J. J., Q. F. Liang, Z. J. Zhou, Z. H. Dai and G. S. Yu; "Numerical and Experimental Investigations on Gas-Particle Flow Behaviors of the Opposed Multi-Burner Gasifier," Energy Convers. Manage., 50, 3035-3044 (2009)

Ni, J. J., G. S. Yu, Q. H. Guo, Z. J. Zhou and F. C. Wang; "Submodel for Predicting Slag Deposition Formation in Slagging Gasification Systems," Energy Fuels, 25, 1004-1009 (2011a)

Ni, J. J., G. S. Yu, Q. H. Guo, Z. H. Dai and F. C. Wang; "Modeling and Comparison of Different Syngas Cooling Types for EntrainedFlow Gasifier," Chem. Eng. Sci., 66, 448-459 (2011b)

Pasandideh-Fard, M., Y. Qiao, S. Chandra and J. Mostaghimi; "Capillary Effects During Droplet Impact on a Solid Surface," Phys. Fluids, 8, 650-659 (1996)

Pasandideh-Fard, M., S. Chandra and J. Mostaghimi; "A Three-Dimensional Model of Droplet Impact and Solidification," Int. J. Heat Mass Transfer, 45, 2229-2242 (2002)

Poirier, D. R. and E. Poirier; "Heat Transfer Fundamentals for Metal Casting," The Minerals, Metals \& Materials Society (TMS), 1992. 90, Warrendale, U.S.A. (1992)

Ranz, W. and W. Marshall; "Evaporation from Drops," Chem. Eng. Prog., 48, 141-146 (1952)

Richards, G. H., P. N. Slater and J. N. Harb; "Simulation of Ash Deposit Growth in a Pulverized Coal-Fired Pilot Scale Reactor," Energy Fuels, 7, 774-781 (1993)

Shih, T.-H., W. W. Liou, A. Shabbir, Z. G. Yang and J. Zhu; "A New $k-\varepsilon$ Eddy Viscosity Model for High Reynolds Number Turbulent Flows," Comput. Fluids, 24, 227-238 (1995)

Šikalo, S., M. Marengo, C. Tropea and E. N. Ganic; "Analysis of Impact of Droplets on Horizontal Surfaces," Exp. Therm. Fluid Sci., 25,
503-510 (2002)

Šikalo, S., C. Tropea and E. N. Ganic; "Impact of Droplets onto Inclined Surfaces," J. Colloid Interface Sci., 286, 661-669 (2005)

Smith, T., Z. Shen and J. Friedman; "Evaluation of Coefficients for the Weighted Sum of Gray Gases Model," J. Heat Transf., 104, 602-608 (1982)

Strandström, K., C. Mueller and M. Hupa; "Development of an Ash Particle Deposition Model Considering Build-Up and Removal Mechanisms," Fuel Process. Technol., 88, 1053-1060 (2007)

Walsh, P. M., A. N. Sayre, D. O. Loehden, L. S. Monroe, J. M. Beer and A. F. Sarofim; "Deposition of Bituminous Coal Ash on an Isolated Heat Exchanger Tube: Effects of Coal Properties on Deposit Growth," Pror. Energy Combust. Sci., 16, 327-345 (1990)

Wang, B., K. W. Chu and A. B. Yu; "Numerical Study of Particle-Fluid Flow in a Hydrocyclone," Ind. Eng. Chem. Res., 46, 4695-4705 (2007)

Wieland, C., B. Kreutzkam, G. Balan and H. Spliethoff; "Evaluation, Comparison and Validation of Deposition Criteria for Numerical Simulation of Slagging," Appl. Energy, 93, 184-192 (2012)

Xu, J., X. Liu, F. Zhao, F. C. Wang, Q. H. Guo and G. S. Yu; "Study on Fusibility and Flow Behavior of High-Calcium Coal Ash," J. Chem. Eng. Japan, 47, 711-716 (2014a)

Xu, J., G. S. Yu, X. Liu, F. Zhao, X. L. Chen and F. C. Wang; "Investigation on the High-Temperature Flow Behavior of Biomass and Coal Blended Ash," Bioresour. Technol., 166, 494-499 (2014b)

Xu, L. H., H. Namkung, H. B. Kwon and H. T. Kim; "Determination of Fouling Characteristics of Various Coals under Gasification Condition," J. Ind. Eng. Chem., 15, 98-102 (2009)

Yong, S. Z., M. Gazzino and A. Ghoniem; "Modeling the Slag Layer in Solid Fuel Gasification and Combustion-Formulation and Sensitivity Analysis," Fuel, 92, 162-170 (2012)

Yong, S. Z. and A. Ghoniem; "Modeling the Slag Layer in Solid Fuel Gasification and Combustion Two-Way Coupling with CFD," Fuel, 97, 457-466 (2012)

Zevenhoven-Onderwater, M., J. P. Blomquist, B. J. Skrifvars, R. Backman and M. Hupa; "The Prediction of Behaviour of Ashes from Five Different Solid Fuels in Fluidised Bed Combustion," Fuel, 79, 1353-1361 (2000) 